\title{
AVALIAÇÃO DE EMPRESAS ESTATAIS E A EVIDENCIAÇÃO DA QUALIDADE DOS GASTOS PÚBLICOS: $O$ caso da CEB Distribuição S.A. ${ }^{1}$
}

\author{
VALUATION OF STATE-CONTROLED COMPANIES AND THE EVINCEMENT OF \\ PUBLIC EXPENSES' QUALITY: The CEB Distribuição S.A.'s case
}

\section{VALORACIÓN DE EMPRESAS ESTATALES Y LA EVIDENCIA DE LA CALIDAD DE LOS GASTOS PÚBLICOS: El caso de CEB Distribuição S.A.}

\author{
Amanda Guimarães Teixeira Silva Schmidt, Graduanda em Ciências Contábeis pela \\ Universidade de Brasília (UnB).E-mail: amanda.agtss@gmail.com.
}

César Augusto Tibúrcio Silva, Doutor em Contabilidade pela Universidade de São Paulo (USP). Endereço Profissional: Universidade de Brasília (UnB), Campus Darcy Ribeiro Prédio da FACE - Sala A1 112 - Brasília, DF - Brasil, CEP 70910900. Telefone: (061) 31070812. URL da Homepage: http://www.ppgcont.unb.br/. E-mail: cesartiburcio@ unb.br.

\section{RESUMO}

Esta pesquisa tem como propósito demonstrar como a ferramenta de avaliação de empresas, pelo método do fluxo de caixa descontado, pode ser utilizada com a finalidade de avaliar a qualidade dos gastos públicos realizados sob a forma de investimentos em empresas estatais. A pesquisa consistiu em um estudo de caso de uma empresa brasileira do setor de energia elétrica, a CEB Distribuição S.A., subsidiária integral de uma sociedade de economia mista. O valor da empresa foi calculado com base em premissas determinadas a partir da análise do desempenho histórico da entidade e projeções macroeconômicas obtidas de outras fontes. Ressalta-se que foram utilizadas somente informações disponíveis ao público. O valor obtido como resultado indica que a entidade analisada não está gerando o retorno financeiro desejável em vista dos recursos públicos nela investidos e permite inferir que o valor recuperável do investimento da controladora nessa empresa é menor do que o valor contábil reconhecido. Essa conclusão pode servir como guia de ação na área pública, pois demonstra a necessidade de melhoria da qualidade dos gastos públicos realizados na empresa analisada, situação que pode se estender a outras empresas estatais brasileiras. Desta forma, sugere-se que sejam realizadas pesquisas utilizando esta metodologia para analisar outras empresas estatais do país.

Palavras-chave: Avaliação de empresas; CEB; Fluxo de caixa descontado; Setor elétrico; Qualidade do gasto público.

\section{ABSTRACT}

This research aimed to demonstrate how the valuation of a company, through method of using the discounted cash flow can be used in order to evaluate the quality of public expenditures in state-controlled companies. This research is a case study of a Brazilian electricity sector company, CEB Distribuição S.A., which is a wholly-owned subsidiary of a mixed-capital corporation. The value of the company was calculated based on assumptions determined by

\footnotetext{
${ }^{1}$ Artigo submetido em 07/08/2017, revisado em 30/09/2017, aceito em 13/11/2017 e divulgado em 15/12/2017 pelo Editor João Carlos Hipólito Bernardes do Nascimento, após double blind review.
}

GєCont, v. 4, n. 1, Floriano-PI, Jan-Jun. 2017. 
the analysis of the company's historical performance and macroeconomic projections obtained from other sources. It must be observed that only information available to general public was used. The obtained value indicates that the analyzed company it is not generating the desirable financial return for the public resources invested in it and permits to infer that the recoverable value of its controller's investment in it is lower than the recognized book value. This conclusion can serve as a guide of action in the public sector as it indicates the need to improve the quality of public expenses on the analyzed company, this situation might be extended to other Brazilian state-controlled companies. Hence, it is suggested that researches be done using this methodology in order to analyze other state-controlled companies of this country.

Key words: Company valuation; CEB; Discounted cash flow: Electricity sector; Quality of public expenditure.

\section{RESUMEN}

Esta pesquisa tiene como propósito demonstrar como a herramienta de valoración de empresas, por el método del flujo de caja descontado, puede ser utilizada con la finalidad de evaluar la calidad de los gastos públicos realizados en forma de inversiones en empresas estatales. La pesquisa consistió en un estudio de caso de una empresa brasileña del sector de energía eléctrica, CEB Distribuição S.A., subsidiaria integral de una sociedad de economía mixta. El valor de la empresa fue calculado con base en premisas determinadas a partir del análisis del desempeño histórico de la entidad y proyecciones macroeconómicas obtenidas de otros orígenes. Se resalta que fueran utilizadas solamente informaciones disponibles al público. El valor obtenido como resultado indica que la entidad analizada no está generando el retorno financiero deseable en vista de los recursos públicos invertidos en ella y permite inferir que el valor recuperable de la inversión de la controladora en esa empresa es menor que el valor contable reconocido. Esa conclusión puede servir como guía de acción en el área pública, pues demuestra la necesidad de mejoría en la calidad de los gastos públicos realizados en la empresa analizada, situación que puede se extender a otras empresas estatales brasileñas. De esta forma, se propone que sean realizadas pesquisas utilizando esta metodología para analizar otras empresas estatales del país.

Palabras clave: Valoración de empresas; CEB; Flujo de caja descontado; Sector eléctrico; Calidad del gasto público.

\section{INTRODUÇÃO}

7 radicionalmente a avaliação de empresas tem sido utilizada no âmbito das empresas privadas com diversas finalidades: compra e venda de empresas, gestão de políticas, decisões de investimento, análise de separação de sócios, entre outras. Ao longo de décadas, a avaliação vem se mostrando como um poderoso conjunto de técnicas capaz de auxiliar a gestão dos negócios e a tomada de decisões. Apesar dos erros cometidos em sua utilização (FERNÁNDEZ, 2007) e das dificuldades oriundas da necessidade de fazer estimativas futuras, a avaliação tem-se firmado a tal ponto que é hoje reconhecida internacionalmente. Prova disto é a existência de um conselho internacional de avaliação denominado International Valuation Standards Council (IVSC).

Especificamente na área de contabilidade a presença das técnicas de avaliação é perceptível no teste de recuperação de ativos, expresso no Brasil por meio do pronunciamento técnico CPC 01 (R1) - Redução ao valor recuperável de ativos (COMITÊ DE PRONUNCIAMENTOS CONTÁBEIS, 2010). De acordo com essa norma de contabilidade, a empresa é obrigada a fazer mensuração do valor em uso dos seus ativos, estimando a geração futura de caixa, descontada por um custo de capital correspondente. Este método nada mais é 
do que a técnica do fluxo de caixa descontado, a mais recomendada para a realização de avaliações.

Apesar da constatação de o conjunto de técnicas de avaliação ser tradicionalmente usado na área privada isto não impede que também seja possível aplicá-lo na área pública, seja no governo central ou em suas empresas. Entretanto, por diversas razões, é possível identificar que o uso tem sido tímido ao longo do tempo, mesmo em países desenvolvidos.

Para o governo, a utilização da avaliação pode ser interessante para determinar a relação custo-benefício de manter uma empresa pública, identificando potenciais áreas para privatização ou encerramento da disponibilidade de bens e serviços. Apesar dos instrumentos usados neste processo serem basicamente os mesmos, o seu uso deve levar em consideração as funções tradicionais do governo: distributiva, alocativa e estabilizadora (MUSGRAVE; MUSGRAVE, 1980).

No caso brasileiro tem-se observado nos últimos anos a concessão de serviços públicos para a iniciativa privada ou a venda de empresas estatais. No primeiro caso têm-se as concessões de rodovias, aeroportos e produção e distribuição de energia elétrica; no passado recente, este processo ocorreu mediante diferentes tipos de leilões. No segundo caso tem-se a privatização, a exemplo do que ocorreu em 2016 com a Celg Distribuição S.A., empresa responsável pela comercialização de energia elétrica no estado de Goiás. Em ambos os casos se faz necessário realizar uma estimativa preliminar de valor de venda, utilizando para isto as técnicas de avaliação.

Um uso alternativo para a avaliação no setor público seria verificar se o serviço prestado está sendo feito com a menor utilização de recursos possíveis. Ou seja, a avaliação pode ajudar a identificar eventuais problemas no desempenho de entidades públicas. Isto diz respeito à questão da gestão dos recursos públicos. De acordo com Abranches (1999, p. 28), "empresas estatais tendem a ser mais minuciosamente reguladas do que as empresas privadas". Assim, elas possuem menor discricionariedade quando comparadas com as empresas privadas. Essa situação deve-se, em grande parte, aos procedimentos burocráticos adicionais que empresas estatais necessitam para realizar a mesma operação que as privadas. Essa necessidade pode impactar negativamente na efetividade, eficiência e eficácia. Outro fator que pode ser relevante é a utilização do setor público para fins políticos, que termina por enfatizar mais as decisões com menor prejuízo político do que àquelas que visam a melhor qualidade dos gastos públicos.

Em razão das dificuldades de mensurar os benefícios sociais de gastos tipicamente públicos, como é o caso de segurança e algumas políticas públicas na área de saúde (vacinação, por exemplo), optou-se por focar num setor em que existe a presença de entidades públicas ao lado de empresas privadas. Esta escolha permite evidenciar melhor os benefícios das técnicas de avaliação, além de possibilitar que seja realizada uma análise comparativa.

Este estudo possui o seguinte problema de pesquisa: é possível usar o fluxo de caixa descontado para evidenciar a qualidade dos gastos públicos?

O objetivo dessa pesquisa é utilizar um estudo de caso no setor elétrico para evidenciar um uso alternativo para a avaliação no setor público: mostrar como as técnicas de avaliação, mais especificamente do fluxo de caixa descontado, podem ser usadas para evidenciar a qualidade dos gastos públicos.

O presente estudo está estruturado em cinco partes. A primeira é esta introdução que visa contextualizar o tema, apresentar o problema de pesquisa, justificar a sua escolha e elencar objetivos. A seguir é feita uma revisão de literatura, que apresenta o fluxo de caixa descontado, destacando as possibilidades de utilização desse método, assim como suas vantagens e desvantagens. Nessa parte também é discutida a questão da utilização do método na área pública. A terceira parte apresenta o proceder metodológico, mais especificamente o tipo de pesquisa realizado, a escolha do estudo de caso e os procedimentos de coleta e análise 
de dados. Na sequência têm-se os resultados da pesquisa. Por fím, são expostas as considerações finais, que evidenciam as conclusões obtidas a partir da análise dos resultados desta pesquisa.

\section{REFERENCIAL TEÓRICO}

\subsection{AVALIAÇÃO DE EMPRESAS}

De acordo com Koller, Goedhart e Wessels (2015), a criação de valor é a medida de desempenho mais expressiva de uma entidade. Segundo esses autores, as empresas que possuem foco na construção de valor para o acionista serão mais saudáveis e contribuirão para a criação de economias mais sólidas. Assim, esse foco é benéfico não só para o acionista e para a empresa, mas para todas as partes interessadas.

Com o intuito de dar enfoque na criação de valor faz-se necessário calcular o valor da entidade. Todavia, conforme Damodaran (2010) o importante para investir nos ativos e gerenciá-los não é somente o valor final encontrado, mas as fontes desse valor. Esse autor considera três métodos de avaliação de empresas: o fluxo de caixa descontado, a avaliação relativa ou por múltiplos e a avaliação por direitos contingentes. Mais recentemente este mesmo autor tem enfatizado os dois primeiros métodos (DAMODARAN, 2011).

Apesar de defender a avaliação por múltiplos, Damodaran (2011) indica os três passos necessários para que esta seja usada: encontrar ativos comparáveis a preço de mercado, relativizar o preço por uma variável comum e ajustar as diferenças. A avaliação relativa é feita, para Damodaran, com menos informação e mais rapidamente que o fluxo de caixa descontado e é mais provável de refletir o humor do mercado no momento atual. Segundo Damodaran, no fluxo de caixa descontado assume-se que o mercado comete erros e que seria possível encontrar estes erros; já na avaliação relativa assume-se que o mercado está correto.

Estas inferências estão corretas se for considerada a avaliação em empresas privadas, especialmente com ações negociadas em bolsa de valores. Na área pública, o grande problema da avaliação por múltiplos é encontrar valores comparáveis; assim, apesar da defesa do múltiplo por parte de Damodaran (2011), este texto irá focar no fluxo de caixa descontado.

De acordo com o fluxo de caixa descontado, o valor de um ativo corresponde ao valor presente dos fluxos de caixa projetados obtidos por este ativo, descontados a uma taxa que reflita o grau de risco desses fluxos. A equação básica para calcular o valor de um ativo qualquer por esse método é apresentada a seguir:

$$
\text { Valor do ativo }=\sum_{t=1}^{n} \frac{F C_{t}}{\left(1+i_{t}\right)^{t}}
$$

Onde:

$F C_{t}=$ Fluxo de caixa previsto no período $t$;

$i_{t}=$ Taxa de desconto no período $t$ que reflete o risco dos fluxos de caixa previstos;

$n=$ Vida útil do ativo.

Esse método mensura o valor intrínseco de um ativo (DAMODARAN, 2004). Segundo Costa, Costa e Alvim (2010), o modelo do fluxo de caixa descontado se sobressai aos demais por apresentar mecanismos essenciais como a tempestividade e a magnitude. A tempestividade faz referência ao tempo em que os fluxos são gerados e sua relação com o valor da empresa. Os fluxos gerados em períodos mais próximos à data da avaliação têm maior impacto no valor da empresa do que os fluxos gerados em períodos remotos. Já a magnitude representa a proporção do fluxo de caixa e a relação entre o valor da empresa e o risco. Quanto maior for o risco, maior será a taxa de desconto e, por consequência, menor será o valor da empresa. 


\subsection{UTILIZAÇÃO DO FLUXO DE CAIXA DESCONTADO}

Existem inúmeras situações em que a utilização da avaliação pelo método do fluxo de caixa descontado mostra-se relevante. Martins et al. (2001) destacam alguns casos em que essa ferramenta se faz útil, quais sejam a compra e venda de negócios, a fusão, cisão e incorporação de empresas, a dissolução de sociedades, a liquidação de empreendimentos, as privatizações e a avaliação da geração de riqueza para os acionistas.

Costa, Costa e Alvim (2010) enfocam a utilização da avaliação como ferramenta de gestão e planejamento financeiro. Santos (2008) aborda outras possíveis finalidades da aplicação desse método de avaliação, como prover sinergia empresarial, reduzir impostos, garantir melhor economia de escala, melhorar condições competitivas e expandir a participação de mercado da empresa investidora.

Martelanc, Pasin e Pereira (2009) elencam ainda outras situações nas quais a avaliação pelo fluxo de caixa descontado é pertinente, quais sejam: formação de parcerias e jointventures, gestão de carteiras de investimento, fundos de private equity e venture capital, abertura e fechamento de capital, liquidação judicial e aquisição de carteiras de cliente e linhas de negócios.

No tocante à utilização do fluxo de caixa descontado no setor público, a International Federation of Acountants - IFAC (2008) destaca que esse método deve ser utilizado para avaliar projetos que envolvem investimentos nos quais os benefícios e custos ocorrem em mais de um período, ou seja, quando existem entradas e saídas de caixa em diversos momentos. Nesses casos, o método do fluxo de caixa descontado é utilizado para calcular o valor presente desses projetos. Esse valor presente é útil como um dos fatores considerados para a realização da análise do custo-benefício de projetos governamentais. Ressalta-se que essa análise para o setor público considera também fatores não monetários, como os impactos sociais dos projetos.

De acordo com o International Valuation Standards Council (2013), muitos ativos especializados em serviços públicos não geram renda para o proprietário, assim torna-se difícil realizar uma avaliação utilizando a abordagem pelos rendimentos. Entretanto, alguns desses ativos são operados em um ambiente comercial e têm como um de seus objetivos prover benefícios econômicos futuros para o proprietário, a exemplo dos ligados a atividades como transporte, eletricidade, gás, água e comunicações. Nesses casos, a abordagem pelos rendimentos é apropriada. Para realizar a avaliação por essa abordagem, o método mais comumente utilizado é o fluxo de caixa descontado.

\subsection{VANTAGENS E DESVANTAGENS DO FLUXO DE CAIXA DESCONTADO}

De acordo com Damodaran (2004) o fluxo de caixa descontado possibilita uma análise rica e minuciosa das diferentes formas pelas quais uma empresa pode aumentar seu valor. Por outro lado, o autor afirma que esse método pode tornar-se demasiadamente complexo quando há um número grande de fatores considerados. Outra desvantagem abordada pelo autor é a dificuldade de vincular remunerações da administração ao valor encontrado por esse modelo, pois muitos fatores necessitam ser estimados e poderiam ser manipulados pela administração para alcançar o resultado desejado.

Martins et al. (2001) abordam alguns aspectos positivos e negativos provenientes da utilização desse método. Segundo esses autores o método é um dos que mais atende ao conceito da utilidade e por meio dele é possível identificar de imediato os elementos patrimoniais que geram riqueza para a entidade. Os autores afirmam, ainda, que quando esse modelo é aplicado com base em valores confiáveis ele se torna insuperável. No que se refere às desvantagens do método, esses autores destacam que o modelo é vulnerável quando 
analisado sob a perspectiva da objetividade e da praticabilidade. Além disso, quando aplicado em itens de permanência prolongada é possível que esse modelo fira o conceito de utilidade. Ademais, o acúmulo de afastamentos, ao longo do tempo, entre os valores praticados na economia e os capitalizados pode gerar informações ilusórias. Por fim, afirmam que o uso generalizado do valor presente dos fluxos de caixa sem a reflexão necessária tende a disseminar comportamentos imediatistas, os quais incentivam a especulação financeira exagerada em detrimento da produção de bens e serviços e de seus benefícios em longo prazo.

O fluxo de caixa descontado é considerado o método mais completo, sendo o mais defendido na literatura acadêmica (PÓVOA, 2012). Além disto, e talvez por isto, é o método usado pelos reguladores, como é o caso da Comissão de Valores Mobiliários (CVM), que por intermédio da Instrução CVM n ${ }^{\mathbf{0}}$ 361/2002 indica explicitamente o método nos processos de avaliação de oferta pública de ações de companhias abertas. Outrossim, esse método é o mais utilizado em processos de alienação de concessões públicas, como aqueles casos relatados na introdução deste trabalho.

\section{METODOLOGIA DE PESQUISA}

\subsection{TIPO DE PESQUISA}

Este estudo é uma pesquisa exploratória de caráter teórico-empírico. De acordo com Gil (2002), o objetivo principal desse tipo de pesquisa seria o refinamento de ideias ou a descoberta de percepções. A pesquisa foi realizada a partir da análise documental das demonstrações contábeis da entidade e de informações obtidas em outras bases de dados; esse tipo de análise utiliza materiais que ainda não receberam tratamento analítico (GIL, 2002).

Além disto, por pretender usar o fluxo de caixa descontado, esta pesquisa pode ser considerada quantitativa. E por usar uma situação específica de uma empresa, trata-se de um estudo de caso. Segundo Yin (2001, p.32), "um estudo de caso é uma investigação empírica que investiga um fenômeno contemporâneo dentro de seu contexto da vida real, especialmente quando os limites entre o fenômeno e o contexto não estão claramente definidos". De acordo com essa definição, considerou-se que essa seria a estratégia de pesquisa mais adequada para atingir os objetivos deste estudo.

Como qualquer outra estratégia, o estudo de caso apresenta vantagens e desvantagens. Por considerar uma situação específica, é realizada uma análise profunda e detalhada de um fenômeno, o que se apresenta como uma vantagem em relação a outros métodos. Porém, uma das principais críticas apresentadas é que um único estudo de caso não fornece base suficiente para generalizações científicas, entretanto, estas poderiam ser obtidas pela análise de casos múltiplos.

\subsection{EMPRESA}

O primeiro critério para escolha da empresa objeto deste estudo de caso é o fato da mesma atuar num setor onde existe a presença de empresas de capital privado. Esta condição facilita a eventual comparação entre os resultados obtidos na pesquisa e aqueles existentes nas empresas privadas. Uma condição acessória era a possível existência de empresas do setor com atuação na bolsa de valores, uma vez que a presença destas empresas no setor de atuação escolhido facilita o cálculo de variáveis necessárias para determinação do valor da empresa objeto de estudo.

O segundo critério é que a empresa escolhida tivesse informações contábeis e não contábeis disponíveis para o usuário externo. E que, na medida do possível, estas informações abrangessem um período de tempo relativamente longo, permitindo a utilização de técnicas 
estatísticas para fazer projeções. Para possibilitar a formulação de projeções confiáveis com base na análise histórica era também fundamental que as informações disponíveis obedecessem às características qualitativas da informação contábil, conforme o Pronunciamento Técnico CPC 00 (R1) - Estrutura Conceitual para Elaboração e Divulgação de Relatório Contábil (COMITÊ DE PRONUNCIAMENTOS CONTÁBEIS, 2011), em particular a relevância e a representação fidedigna. Como estas características são difíceis de serem mensuradas, considerou-se como uma condição necessária que a empresa tivesse auditoria externa.

Por satisfazer as duas condições (atuação num setor com presença de capital privado e informações disponíveis auditadas) optou-se por utilizar a CEB Distribuição S.A.. Atuando no setor de energia elétrica, essa empresa foi constituída em 20 de junho de 2005, com início das atividades em 12 de janeiro de 2006. Sua constituição ocorreu como resultado da reestruturação societária da Companhia Energética de Brasília (CEB), dada pela Lei $\mathrm{n}^{\circ}$ 10.848, de 15 de março de 2004 e aprovada pela Resolução Autorizativa no 318/2005 da Agência Nacional de Energia Elétrica (ANEEL). Após a reestruturação, a Companhia Energética de Brasília passou ser a holding, controlando as empresas do "Grupo CEB", incluindo a CEB Distribuição S.A., esta voltada para a distribuição e comercialização de energia elétrica no Distrito Federal.

A CEB Distribuição S.A. é caracterizada como uma sociedade anônima de capital fechado, tendo como único acionista a Companhia Energética de Brasília. A Companhia Energética de Brasília, por sua vez, é uma sociedade anônima de capital aberto que possui ações negociadas na B3 (Brasil, Bolsa, Balcão). De acordo com o sítio eletrônico da B3, em 10 de maio de 2017 o Governo do Distrito Federal possuía 93,21\% das ações ordinárias da Companhia Energética de Brasília. Assim, essa empresa é considerada uma sociedade de economia mista, pois é constituída de capital predominantemente público, mas possui também capital privado. Dessa forma, a CEB Distribuição S.A. é indiretamente controlada pelo Governo do Distrito Federal, sendo qualificada como uma empresa estatal. A expressão empresa estatal não possui um conceito definido juridicamente, sendo que a doutrina entende majoritariamente que essa nomenclatura se aplica a entidades controladas direta ou indiretamente pelo Estado (PIRES, 2012).

A CEB Distribuição S.A. é uma empresa que possui dados divulgados desde seu primeiro ano de atividade, sendo possível analisar uma série histórica de onze anos, de 2006 a 2016. Outro fato que torna a escolha da CEB Distribuição S.A. relevante é que recentemente houve a privatização de uma empresa do setor, conforme informado na introdução do trabalho. Um fator de interesse que inicialmente não tinha sido considerado como critério de escolha refere-se ao fato de que a CEB Distribuição S.A. é um investimento da Companhia Energética de Brasília. Desta forma, o cálculo do valor dessa empresa poderia funcionar como um teste de recuperação desse ativo para a investidora: Companhia Energética de Brasília.

\subsection{PROCEDIMENTOS DE COLETA E ANÁLISE DE DADOS}

Com o intuito de calcular o valor da CEB Distribuição S.A. foi realizada primeiramente uma análise histórica das demonstrações financeiras da Companhia, de 2006 a 2016. As demonstrações financeiras consideradas foram o Balanço Patrimonial, a Demonstração do Resultado do Exercício e a Demonstração dos Fluxos de Caixa. Todos os dados das demonstrações foram obtidos no sítio eletrônico da Companhia Energética de Brasília. Assim, o processo de avaliação foi conduzido sob a ótica do usuário externo. Esse sítio, em 15 de maio de 2017, disponibilizava as demonstrações e os relatórios da administração anuais de 2006 a 2016 e trimestrais desde o primeiro trimestre de 2013 até o quarto trimestre de 2016. 
Assim, foram elaboradas planilhas com as informações coletadas, anuais de 2006 a 2016 e trimestrais de 2013 a 2016. Para a elaboração dessas planilhas foram utilizadas as demonstrações mais recentes disponíveis para os casos de demonstrações que foram reapresentadas ou cujos valores ou classificações sofreram pequenas alterações.

A partir do exame dessas planilhas, juntamente com outras publicações da empresa, como comentários de desempenho, relatórios da administração e notas explicativas, realizouse uma análise histórica da entidade. Essa análise consistiu na etapa inicial da pesquisa, que fundamentou os demais procedimentos realizados. As etapas para o cálculo e análise do valor da empresa são listadas a seguir: a) análise do desempenho passado da empresa; b) projeção dos fluxos de caixa futuros; c) estimativa da taxa de desconto; d) cálculo do valor da empresa; e) análise de sensibilidade do valor da empresa.

A projeção dos fluxos de caixa futuros foi iniciada a partir da conta "Recebimento de consumidores", constante na Demonstração dos Fluxos de Caixa. Optou-se por relacionar este valor com a população projetada do Distrito Federal, conforme dados do Instituto Brasileiro de Geografia e Estatística (IBGE). Para encontrar um modelo representativo dessa relação foi utilizado o software Gretl ${ }^{\circledR}$. Os demais valores de recebimentos e pagamentos foram projetados a partir dessa conta, fazendo uma análise histórica do comportamento dos principais itens.

Para calcular a taxa de desconto estimada foram considerados, além da análise histórica, dados de companhias de capital aberto do setor de energia elétrica, obtidos pelo software Economática ${ }^{\circledR}$, pesquisas no sítio eletrônico da B3, projeções de inflação publicadas no Diário Oficial da União e projeções de longo prazo elaboradas pelo Banco Bradesco S.A.. $\mathrm{O}$ uso dos dados desta instituição financeira deveu-se a sua disponibilidade e por considerar que os números usados teriam grau de confiança adequado. Para a realização da análise de sensibilidade foi utilizada também a base de dados macroeconômica Ipeadata, do Instituto de Pesquisa Econômica Aplicada (Ipea).

Optou-se por trabalhar, sempre que possível, com estimativas futuras oficiais de variáveis como crescimento da economia, inflação, entre outras. Acredita-se que esta opção não afeta a qualidade dos resultados obtidos. De igual forma, parte-se da suposição que o consumo do principal produto da CEB Distribuição S.A. deverá guardar uma correspondência com o crescimento da população. Eventuais mudanças tecnológicas, como a utilização de energia alternativa ou o desenvolvimento de aparelhos eletrônicos com consumo mais eficiente podem afetar a projeção.

Após o cálculo do valor da empresa foi realizada uma análise de sensibilidade no intuito de identificar como alterações em determinados itens afetariam o valor total da empresa. Esta análise utilizou a Simulação de Monte Carlo (SMC), que considera os valores como probabilísticos. Para isto, utilizou-se o software Oracle Crystal Ball ${ }^{\circledR}$ que permite a utilização de diversas distribuições de probabilidades para as variáveis utilizadas no cálculo do valor da empresa, além de determinar as variáveis mais relevantes para o resultado final obtido. Os resultados dessa simulação permitem calibrar melhor os valores de cada uma das variáveis e destacar, de forma mais incisiva, quais montantes projetados são mais relevantes.

Faz-se necessário destacar que a avaliação consiste em uma opinião formada com base em certos pressupostos que dão suporte as projeções futuras elaboradas. Se esses pressupostos forem alterados, como pela modificação ou surgimento de informações, o valor encontrado para a empresa pode ser diferente. Assim sendo, é necessário ressaltar que a avaliação constante no presente estudo tem como data-base 31 de dezembro de 2016, data das últimas demonstrações contábeis consideradas na análise histórica. Ressalta-se que a coleta dos demais dados utilizados nesta pesquisa encerrou-se em maio de 2017.

Finalmente, a avaliação parte do pressuposto de que a CEB Distribuição S.A. continuará com o atual status quo. Ou seja, o processo de gestão da empresa se manterá nos 
próximos anos, assim como o setor onde a empresa atua não deverá sofrer mudanças substanciais. Alterações nestas condições demandariam uma nova avaliação.

\subsection{FLUXO DE CAIXA DESCONTADO}

A equação básica para calcular o valor de um ativo por esse método foi apresentada no referencial teórico. Em sua formulação mais completa, utilizada para calcular o valor de uma empresa, parte-se do pressuposto da continuidade dessa empresa. Dessa forma, o período de tempo tende a infinito. Como não é possível projetar fluxos de caixa infinitos, faz-se uma adaptação de modo a projetar os fluxos de caixa até um período $n$ e calcular os demais considerando o fluxo de caixa do período $n$ e uma taxa de crescimento constante.

Esse valor estimado para os períodos posteriores ao período $n$ é trazido a valor presente do período $n$ pela fórmula da perpetuidade, considerando taxa de crescimento dos fluxos de caixa $g$, do inglês growth, e em seguida descontado novamente para representar o valor presente no momento do cálculo do valor da empresa. Assim, considerando os ajustes mencionados, a fórmula do valor da empresa é a que segue:

$$
\text { Valor }=\sum_{t=1}^{n}\left(\frac{F C_{t}}{\left(1+i_{t}\right)^{t}}\right)+\frac{\frac{F C_{n+1}}{i_{n}-g}}{\left(1+i_{n}\right)^{n}}
$$

A partir da análise dessa fórmula, nota-se que o valor de uma empresa calculado pelo fluxo de caixa descontado depende dos fluxos de caixa projetados e da taxa de desconto utilizada. Conforme Fernández (2002) existem diversos métodos para obter o valor de uma empresa; este autor mostra que em todos os casos, o resultado final deverá ser o mesmo, desde que os pressupostos sejam idênticos. Fernández (2002) demonstra que é possível obter o valor do capital próprio usando o fluxo de caixa do acionista, descontado pelo custo do capital próprio. O valor da empresa seria dado pelo valor do capital próprio mais o valor da dívida. Um segundo método seria descontar o fluxo de caixa livre pelo custo médio ponderado do capital (WACC, do inglês Weighted Average Cost of Capital). Outra forma é usar o fluxo de capital, descontado pelo WACC livre de impostos. Um quarto método, proposto por Myers (1974), é o valor presente ajustado (APV, do inglês Adjusted Present Value), pelo qual se obtém o valor da empresa sem dívidas e se soma o benefício da dívida. Um quinto método é obter o lucro econômico a valor presente. Finalmente, também é possível obter o valor a partir do lucro líquido após a remuneração dos acionistas, trazido a valor presente.

No presente trabalho, optou-se por calcular o valor da empresa a partir do fluxo de caixa do acionista projetado usando como taxa de desconto o custo do capital próprio. Entre as diferentes formas de obtenção deste custo, optou-se por usar o Capital Asset Pricing Model (CAPM). Para obter o valor da empresa, basta somar o valor do capital próprio (valor da empresa para o acionista) às dívidas existentes.

Para as projeções de fluxo de caixa seria possível começar projetando a receita líquida, constante na Demonstração do Resultado do Exercício, ou o recebimento de consumidores, da Demonstração dos Fluxos de Caixa, já que a empresa apresenta essa demonstração pelo método direto.

Para decidir entre projetar a Demonstração do Resultado do Exercício ou a Demonstração dos Fluxos de Caixa foram coletados dados de três outras variáveis, no período anual de 2006 a 2016 e trimestral de 2013 a 2016, que pudessem estar relacionadas aos valores dessas contas. Essas três variáveis foram: a população do Distrito Federal, de acordo com o Instituto Brasileiro de Geografia e Estatística, o consumo total e o número total de consumidores da energia elétrica comercializada pela CEB Distribuição S.A., estes dois obtidos dos comentários de desempenho e relatórios da administração da entidade. Destaca-se 
que o número total de consumidores não representa o número de pessoas que consomem emergia elétrica, mas sim o número de unidades consumidoras, como residências e comércios.

Em seguida, foram calculadas correlações entre consumo, número total de consumidores, população do Distrito Federal, receita líquida e recebimento de consumidores, tomados dois a dois. Os coeficientes de correlação obtidos estão apresentados na Tabela 1.

Tabela 1 - Coeficientes de correlação

\begin{tabular}{|c|c|c|c|c|c|}
\hline \multicolumn{6}{|c|}{ Coeficientes de correlação anual de 2006 a 2016} \\
\hline & $\begin{array}{l}\text { População } \\
\text { do DF }\end{array}$ & $\begin{array}{c}\text { Recebimento } \\
\text { de } \\
\text { consumidores }\end{array}$ & $\begin{array}{l}\text { Receita } \\
\text { líquida }\end{array}$ & $\begin{array}{c}\text { Consumo } \\
\text { de energia } \\
\text { (GWh) }\end{array}$ & $\begin{array}{c}\text { Número total } \\
\text { de } \\
\text { consumidores }\end{array}$ \\
\hline População do DF & 1,000 & 0,927 & 0,970 & 0,955 & 1,000 \\
\hline Recebimento de consumidores & & 1,000 & 0,931 & 0,793 & 0,925 \\
\hline Receita líquida & & & 1,000 & 0,915 & 0,974 \\
\hline Consumo de energia (GWh) & & & & 1,000 & 0,955 \\
\hline Número total de consumidores & & & & & 1,000 \\
\hline \multicolumn{6}{|c|}{ Coeficientes de correlação trimestral do $1^{\circ}$ trimestre de 2013 ao $4^{\circ}$ trimestre de 2016} \\
\hline & $\begin{array}{c}\text { População } \\
\text { do DF }\end{array}$ & $\begin{array}{c}\text { Recebimento } \\
\text { de } \\
\text { consumidores }\end{array}$ & $\begin{array}{l}\text { Receita } \\
\text { líquida }\end{array}$ & $\begin{array}{c}\text { Consumo } \\
\text { de energia } \\
(\mathrm{GWh})\end{array}$ & $\begin{array}{c}\text { Número total } \\
\text { de } \\
\text { consumidores }\end{array}$ \\
\hline População do DF & 1,000 & 0,896 & 0,645 & 0,239 & 0,996 \\
\hline Recebimento de consumidores & & 1,000 & 0,660 & 0,279 & 0,893 \\
\hline Receita líquida & & & 1,000 & 0,305 & 0,675 \\
\hline Consumo de energia (GWh) & & & & 1,000 & 0,261 \\
\hline Número total de consumidores & & & & & 1,000 \\
\hline
\end{tabular}

GWh - Gigawatt-hora

Fonte: Elaboração própria

As correlações foram calculadas separadamente, com os dados anuais de 2006 a 2016 e os dados trimestrais de 2013 a 2016, com o objetivo de observar quais apresentavam maior correlação.

Observa-se, pela análise da Tabela 1, que as maiores correlações foram encontradas utilizando-se os dados anuais. Portanto, decidiu-se utilizar os dados anuais para fazer as projeções de fluxo de caixa anual da CEB Distribuição S.A..

\section{RESULTADOS E ANÁLISE}

O processo de cálculo do valor iniciou-se pela projeção do recebimento de consumidores. Utilizou-se uma regressão entre esta variável e a população projetada do Distrito Federal, a partir de cálculo realizado com dados passados. As demais contas da Demonstração dos Fluxos de Caixa foram projetadas com base nos percentuais históricos que elas apresentavam em relação à conta "Recebimento de consumidores". As contas pertencentes ao fluxo de caixa das atividades operacionais foram agrupadas em quatro grandes grupos enquanto os outros fluxos, de investimento e de financiamento, foram considerados pelos seus totais, por apresentarem valores pouco expressivos.

As Demonstrações dos Fluxos de Caixa foram projetadas para o período de 2017 a 2030. As variações de caixa e equivalentes encontradas foram positivas e crescentes, porém com valores pouco expressivos.

A Tabela 2 apresenta o cálculo do valor da empresa para o acionista a partir do Fluxo de Caixa do Acionista e do Custo do Capital Próprio projetados para cada ano. 
Tabela 2 - Cálculo do valor da empresa para o acionista em milhões de reais

\begin{tabular}{ccccc}
\hline Ano & FCA & $\mathbf{1 + \mathbf { K } _ { \mathbf { e } }}$ & $\mathbf{1 + \mathbf { K } _ { \mathbf { e } } \text { acumulado }}$ & $\mathbf{V P}(\mathbf{F C A})$ \\
\hline 2017 & $\mathrm{R} \$ 7$ & 1,1346 & 1,1346 & $\mathrm{R} \$ 5,986$ \\
2018 & $\mathrm{R} \$ 7$ & 1,1394 & 1,2928 & $\mathrm{R} \$ 4,319$ \\
2019 & $\mathrm{R} \$ 8$ & 1,1360 & 1,4687 & $\mathrm{R} \$ 2,412$ \\
2020 & $\mathrm{R} \$ 8$ & 1,1370 & 1,6700 & $\mathrm{R} \$ 1,037$ \\
2021 & $\mathrm{R} \$ 8$ & 1,1372 & 1,8991 & $\mathrm{R} \$ 0,343$ \\
2022 & $\mathrm{R} \$ 9$ & 1,1372 & 2,1597 & $\mathrm{R} \$ 0,088$ \\
2023 & $\mathrm{R} \$ 9$ & 1,1372 & 2,4561 & $\mathrm{R} \$ 0,017$ \\
2024 & $\mathrm{R} \$ 10$ & 1,1372 & 2,7932 & $\mathrm{R} \$ 0,003$ \\
2025 & $\mathrm{R} \$ 10$ & 1,1372 & 3,1765 & $\mathrm{R} \$ 0,000$ \\
2026 & $\mathrm{R} \$ 10$ & 1,1372 & 3,6124 & $\mathrm{R} \$ 0,000$ \\
2027 & $\mathrm{R} \$ 11$ & 1,1372 & 4,1081 & $\mathrm{R} \$ 0,000$ \\
2028 & $\mathrm{R} \$ 11$ & 1,1372 & 4,6719 & $\mathrm{R} \$ 0,000$ \\
2029 & $\mathrm{R} \$ 12$ & 1,1372 & 5,3130 & $\mathrm{R} \$ 0,000$ \\
Perpetuidade a partir de 2030 & $\mathrm{R} \$ 12$ & 1,1372 & 6,0421 & $\mathrm{R} \$ 0,000$ \\
\hline
\end{tabular}

FCA - fluxo de caixa do acionista

$\mathrm{K}_{\mathrm{e}}$ - custo do capital próprio

$\mathrm{VP}$ - valor presente

VEA - valor da empresa para o acionista

Fonte: Elaboração própria

Considerou-se, por simplificação, que a empresa distribuirá o caixa gerado em forma de dividendos; assim, o fluxo de caixa do acionista foi considerado como o somatório do fluxo de caixa operacional e do fluxo de caixa de investimento. Essa suposição tende a superestimar o resultado obtido.

Para a projeção do custo do capital próprio obteve-se valores diferentes a cada ano, que variaram de $13,46 \%$ a $13,94 \%$. Estes valores estão baseados em premissas consideradas realistas para a atual situação da CEB Distribuição S.A..

O resultado obtido após o cálculo do valor da empresa para o acionista foi $\mathrm{R} \$ 14$ milhões. Conforme dito anteriormente, para calcular o valor da empresa deve-se somar ao valor da empresa para o acionista a dívida total da empresa, representada pelo total de seus passivos onerosos. O valor da dívida da CEB Distribuição S.A. em 31 de dezembro de 2016 era R \$ 702 milhões. Dessa forma o valor da empresa encontrado foi $\mathrm{R} \$ 716$ milhões.

Vale ressaltar que esse valor foi obtido a partir de pressupostos que consideraram principalmente o desempenho histórico da entidade, além de projeções e dados de outras fontes. Assim, esse valor corresponde ao valor presente da companhia caso ela continue seguindo a linha histórica, sem realizar mudanças significativas na gestão, que poderiam alterar o referido valor.

Considerando-se, por simplificação, que o valor do investimento da controladora integral Companhia Energética de Brasília na empresa analisada CEB Distribuição S.A. corresponde ao valor do patrimônio líquido total da CEB Distribuição S.A., tem-se que o retorno calculado pelo fluxo de caixa do acionista projetado trazido a valor presente é menor do que o valor investido. O valor do patrimônio líquido da CEB Distribuição S.A. em 31 de dezembro de 2016 era $\mathrm{R} \$ 359$ milhões e o valor da empresa para o acionista calculado pelo fluxo de caixa descontado foi de R $\$ 14$ milhões, que corresponde a aproximadamente $4 \%$ do valor do patrimônio líquido da entidade. Esse cenário permite inferir que o valor recuperável do investimento da controladora na CEB Distribuição S.A. seria menor do que seu valor contábil. 
O valor da empresa encontrado de $\mathrm{R} \$ 716$ milhões representa o retorno estimado trazido a valor presente do investimento total na empresa. Esse investimento, representado pela soma do patrimônio líquido da empresa com a dívida total, em 31 de dezembro de 2016, correspondia a R \$ 1.061 milhões. Se comparados esses dois valores tem-se que o retorno calculado é menor do que o valor contábil do investimento, representando aproximadamente $67 \%$ deste.

O valor da empresa calculado pelo fluxo de caixa descontado pode ser utilizado para evidenciar a qualidade dos gastos públicos realizados pelo Governo do Distrito Federal na CEB Distribuição S.A., indiretamente, por meio de seus investimentos na controladora Companhia Energética de Brasília. De acordo com o resultado obtido, esses gastos não produzirão o retorno esperado do ponto de vista econômico-financeiro. Essa situação representa um impacto financeiro negativo para o Governo do Distrito Federal e para a população que contribui com impostos, os quais representam a maior parcela das receitas públicas, podendo ser entendida como transferência de renda.

Como a empresa não está gerando o retorno esperado, sua continuidade pode ter caráter duvidoso. Em relação a esse assunto, os auditores independentes da CEB Distribuição S.A. destacaram no relatório emitido em 27 de março de 2017, disponível no sítio eletrônico da companhia, a existência de incerteza relevante quanto à continuidade operacional da empresa, devido ao seu histórico de deficiência de capital de giro e alto índice de endividamento, além da necessidade de frequentes investimentos para a realização de suas atividades em decorrência de características inerentes à sua atividade operacional e de exigências dos órgãos concedente e regulador.

Os planos da administração para manutenção de suas atividades foram descritos na Nota Explicativa $\mathrm{n}^{\circ} 1.7$ referente às demonstrações contábeis anuais do exercício findo em 2016, também disponíveis no sítio eletrônico da companhia. Essa nota trata de um plano de trabalho idealizado em 2015, composto por três fases: ajustes pontuais, realizados em 2015; ajustes estruturais que incluíram redução da estrutura organizacional e otimização de atividades; e reorganização societária do Grupo "CEB" que consistirá na alienação de ativos de geração de energia elétrica e de distribuição de gás, prevista para 2017.

\subsection{ANÁLISE DE SENSIBILIDADE COM BASE EM ALTERAÇÃO HIPOTÉTICA DE VALORES}

Deve-se ter em mente que o valor de uma empresa calculado pelo método do fluxo de caixa descontado é obtido a partir de projeções futuras realizadas com base em premissas e, consequentemente, carrega elevado grau de incerteza, pois as projeções podem ou não se concretizar. Portanto, faz-se necessário analisar diferentes cenários possíveis e os impactos que eles causariam ao valor da empresa, dando destaque aos aspectos mais relevantes, ou seja, aqueles que mais influenciam o valor da entidade. Por esse motivo, realizou-se a análise de sensibilidade dos cálculos realizados anteriormente.

Para realizar esta análise, os valores projetados foram revistos, dando destaque aqueles considerados mais sensíveis. Tome, por exemplo, o item "Fornecedores - Energia elétrica", que corresponde ao gasto mais relevante realizado pela empresa, representando 45,07\% do recebimento de consumidores projetado. Existe a possibilidade de que esse gasto seja aumentado ou reduzido no futuro. Considerando, por exemplo, que o valor dessa conta corresponda a $40 \%$ do recebimento de consumidores podemos calcular novamente o valor da empresa, mantendo todas as demais variáveis constantes.

Utilizando-se esse percentual tem-se uma projeção em que o saldo líquido de caixa e equivalentes de caixa apresenta valores positivos e crescentes bem mais expressivos do que os 
valores obtidos anteriormente. Assim, o fluxo de caixa do acionista se altera nos anos projetados, enquanto o custo do capital próprio permanece o mesmo.

A Tabela 3 apresenta o cálculo do valor da empresa para o acionista nessa hipótese.

Tabela 3 - Cálculo do valor da empresa para o acionista com redução do percentual da conta "Fornecedores - Energia elétrica" em milhões de reais

\begin{tabular}{llccc}
\hline \multicolumn{1}{c}{ Ano } & FCA & $\mathbf{1}+\mathbf{K}_{\mathbf{e}}$ & $\mathbf{1}+\mathbf{K}_{\mathbf{e}}$ acumulado & VP (FCA) \\
\hline 2017 & $\mathrm{R} \$ 179$ & 1,1346 & 1,1346 & $\mathrm{R} \$ 157,723$ \\
2018 & $\mathrm{R} \$ 190$ & 1,1394 & 1,2928 & $\mathrm{R} \$ 113,809$ \\
2019 & $\mathrm{R} \$ 201$ & 1,1360 & 1,4687 & $\mathrm{R} \$ 63,566$ \\
2020 & $\mathrm{R} \$ 212$ & 1,1370 & 1,6700 & $\mathrm{R} \$ 27,314$ \\
2021 & $\mathrm{R} \$ 223$ & 1,1372 & 1,8991 & $\mathrm{R} \$ 9,041$ \\
2022 & $\mathrm{R} \$ 234$ & 1,1372 & 2,1597 & $\mathrm{R} \$ 2,307$ \\
2023 & $\mathrm{R} \$ 245$ & 1,1372 & 2,4561 & $\mathrm{R} \$ 0,454$ \\
2024 & $\mathrm{R} \$ 255$ & 1,1372 & 2,7932 & $\mathrm{R} \$ 0,069$ \\
2025 & $\mathrm{R} \$ 265$ & 1,1372 & 3,1765 & $\mathrm{R} \$ 0,008$ \\
2026 & $\mathrm{R} \$ 275$ & 1,1372 & 3,6124 & $\mathrm{R} \$ 0,001$ \\
2027 & $\mathrm{R} \$ 285$ & 1,1372 & 4,1081 & $\mathrm{R} \$ 0,000$ \\
2028 & $\mathrm{R} \$ 295$ & 1,1372 & 4,6719 & $\mathrm{R} \$ 0,000$ \\
2029 & $\mathrm{R} \$ 304$ & 1,1372 & 5,3130 & $\mathrm{R} \$ 0,000$ \\
Perpetuidade a partir de 2030 & $\mathrm{R} \$ 313$ & 1,1372 & 6,0421 & $\mathrm{R} \$ 0,000$ \\
\hline & TOTAL (VEA) & & & $\mathrm{R} \$ \mathbf{3 7 4 , 2 9 2}$ \\
\hline
\end{tabular}

FCA - fluxo de caixa do acionista

$\mathrm{K}_{\mathrm{e}}$ - custo do capital próprio

$\mathrm{VP}$ - valor presente

VEA - valor da empresa para o acionista

Fonte: Elaboração própria

Como resultado, o valor da empresa para o acionista seria $\mathrm{R} \$ 374$ milhões, passando a ser superior ao valor do patrimônio líquido da empresa ( $\mathrm{R} \$ 359$ milhões). Considerando a dívida total de R 702 milhões, o valor da empresa corresponde a R \$ 1.076 milhões, esse valor é superior ao valor do investimento total da entidade, de $\mathrm{R} \$ 1.061$ milhões.

\subsection{ANÁlisE DE SENSIBILIDADE COM BASE NA SIMULAÇÃO DE MONTE CARLO}

Seria possível realizar infinitos cálculos de valor da empresa a partir de suposições como a redução do percentual da conta "Fornecedores - Energia elétrica", demonstrada no tópico anterior. Essas suposições poderiam ser alterações de valor de somente uma variável, combinações de alteração do valor de duas ou mais variáveis ou até de todas as variáveis simultaneamente. Realizar todas essas simulações seria humanamente impossível e tentar aproximar-se de um número grande de simulações seria extremamente trabalhoso.

Por esse motivo, realiza-se a Simulação de Monte Carlo. Essa simulação, de acordo com Souza (2004), caracteriza-se como um método de simulação estatística que produz soluções aproximadas para um problema. Ela fornece resultados possíveis juntamente com a probabilidade de ocorrência de cada um. No caso da presente pesquisa, essa simulação foi utilizada para encontrar possíveis valores da empresa analisada e suas respectivas probabilidades.

Os pressupostos utilizados para cada variável que exerceu influência no cálculo do valor da CEB Distribuição S.A. estão apresentados de forma sintetizada na Tabela 4 e são explicados detalhadamente em seguida.

GєCont, v. 4, n. 1, Floriano-PI, Jan-Jun. 2017. 
Tabela 4 - Pressupostos utilizados para cada variável

\begin{tabular}{lccc}
\hline \multicolumn{1}{c}{ Variável } & Distribuição & Média & Desvio padrão \\
\hline Recebimento de consumidores & Normal & Diferente em cada ano & 736 \\
Fornecedores - Energia elétrica & Normal & $-45,07 \%$ & $7,88 \%$ \\
Outras contas operacionais & Normal & $-30,02 \%$ & $4,74 \%$ \\
Impostos e contribuições & Normal & $-22,09 \%$ & $2,30 \%$ \\
Caixa líquido proveniente das atividades de & Normal & $-2,62 \%$ & $1,64 \%$ \\
investimento & Normal & 0,50 & 0,22 \\
Beta não alavancado $\left(\beta_{\mathrm{NA}}\right)$ & Normal & $24,67 \%$ & $2,47 \%$ \\
Alíquota projetada IR, no caso em que FCA $>0$ & Normal & 1,89 & 0,52 \\
Relação D/E projetada & Normal & Diferente em cada ano & $2,21 \%$ \\
Taxa livre de risco $\left(\mathrm{R}_{\mathrm{f}}\right)$ & Normal & Diferente em cada ano & $20 \%$ \\
Retorno do mercado $\left(\mathrm{R}_{\mathrm{m}}\right)$ & Normal & $2,99 \%$ & $12,88 \%$ \\
Taxa de crescimento constante $(\mathrm{g})$ & & & \\
\hline
\end{tabular}

IR - imposto de renda

FCA - fluxo de caixa do acionista

$\mathrm{D} / \mathrm{E}$ - debt to equity ratio (índice da dívida sobre o patrimônio líquido)

Fonte: Elaboração própria

Para as contas que compõem os fluxos de caixa provenientes das atividades operacionais e de investimento da Demonstração dos Fluxos de Caixa projetada utilizou-se a distribuição normal. A média considerada para a conta "Recebimento de consumidores" foi o valor projetado para cada ano e o desvio padrão foi o calculado com base nos valores que essa conta apresentou na série histórica analisada, de 2006 a 2016. Para as demais contas a média considerada foi o percentual utilizado para a projeção de cada conta em relação à conta "Recebimento de consumidores" e o desvio padrão foi o dos percentuais obtidos na série histórica.

Considerou-se que no caso do somatório do fluxo de caixa operacional com o fluxo de caixa de investimento ser negativo o fluxo de caixa do acionista seria igual à zero, pois não haveria distribuição de dividendos, já que essa distribuição seria incompatível com a situação financeira da Companhia, conforme do parágrafo $4^{\circ}$ do artigo 202 da Lei 6.404/76. No caso dessa soma resultar em um valor positivo, o fluxo de caixa do acionista seria esse próprio valor, partindo do pressuposto de que nesse caso, todas as disponibilidades seriam distribuídas como dividendos.

O próximo passo foi definir os pressupostos das variáveis utilizadas no cálculo do beta alavancado projetado $\left(\beta_{\mathrm{AP}}\right)$. Para o beta não alavancado $\left(\beta_{\mathrm{NA}}\right)$ utilizou-se a distribuição normal, tendo como média o valor projetado, de 0,50 . É importante ressaltar que esse valor corresponde à média dos betas das empresas de energia elétrica controladas pelo Estado. Portanto, o desvio padrão considerado foi o obtido a partir dessa mesma amostra, que correspondeu a 0,22. Para a alíquota projetada do Imposto de Renda considerou-se que nos casos em que o fluxo de caixa do acionista fosse negativo ela seria igual à zero; em sendo positivo foi considerada uma distribuição normal, cuja média foi $24,67 \%$ em todos os períodos, que corresponde ao valor médio da taxa efetiva de imposto pago por empresas lucrativas no Brasil (DAMODARAN, 2017). Como pressuposto do índice da dívida sobre o patrimônio líquido (D/E) projetado considerou-se também a distribuição normal, com média de 1,89 , que corresponde ao valor projetado, e desvio padrão dessa relação na série histórica, desconsiderando valores extremos atípicos, que correspondeu a 0,52.

Em seguida foram determinados os pressupostos das demais variáveis necessárias para calcular o custo do capital próprio $\left(\mathrm{K}_{\mathrm{e}}\right)$, ou seja, a taxa livre de risco $\left(\mathrm{R}_{\mathrm{f}}\right)$ e o retorno do mercado $\left(\mathrm{R}_{\mathrm{m}}\right)$. Para essas duas variáveis considerou-se também a distribuição normal, a média foi o valor projetado de cada variável para os anos 2017 a 2030. O desvio padrão utilizado foi obtido a partir da série histórica de 2006 a 2016 da taxa Selic (Sistema Especial de Liquidação e de Custódia), no caso da taxa livre de risco, e da série de 2010 a 2016 do Índice Bovespa (Ibovespa), para o retorno do mercado. Ambas as séries históricas foram obtidas da base de 
dados macroeconômica Ipeadata, do Instituto de Pesquisa Econômica Aplicada. Por fim, foi definido o pressuposto da taxa de crescimento na perpetuidade $(g)$, considerando uma distribuição normal, tendo como média o valor projetado, de 2,99\%; o desvio padrão foi calculado a partir das taxas de crescimento anuais apresentadas pela empresa, de 2006 a 2016, esse valor correspondeu a $12,88 \%$.

Foram realizadas 50.000 simulações. O resultado obtido para a previsão do valor da empresa está apresentado no Gráfico 1.

Gráfico 1 - Previsão do valor da empresa

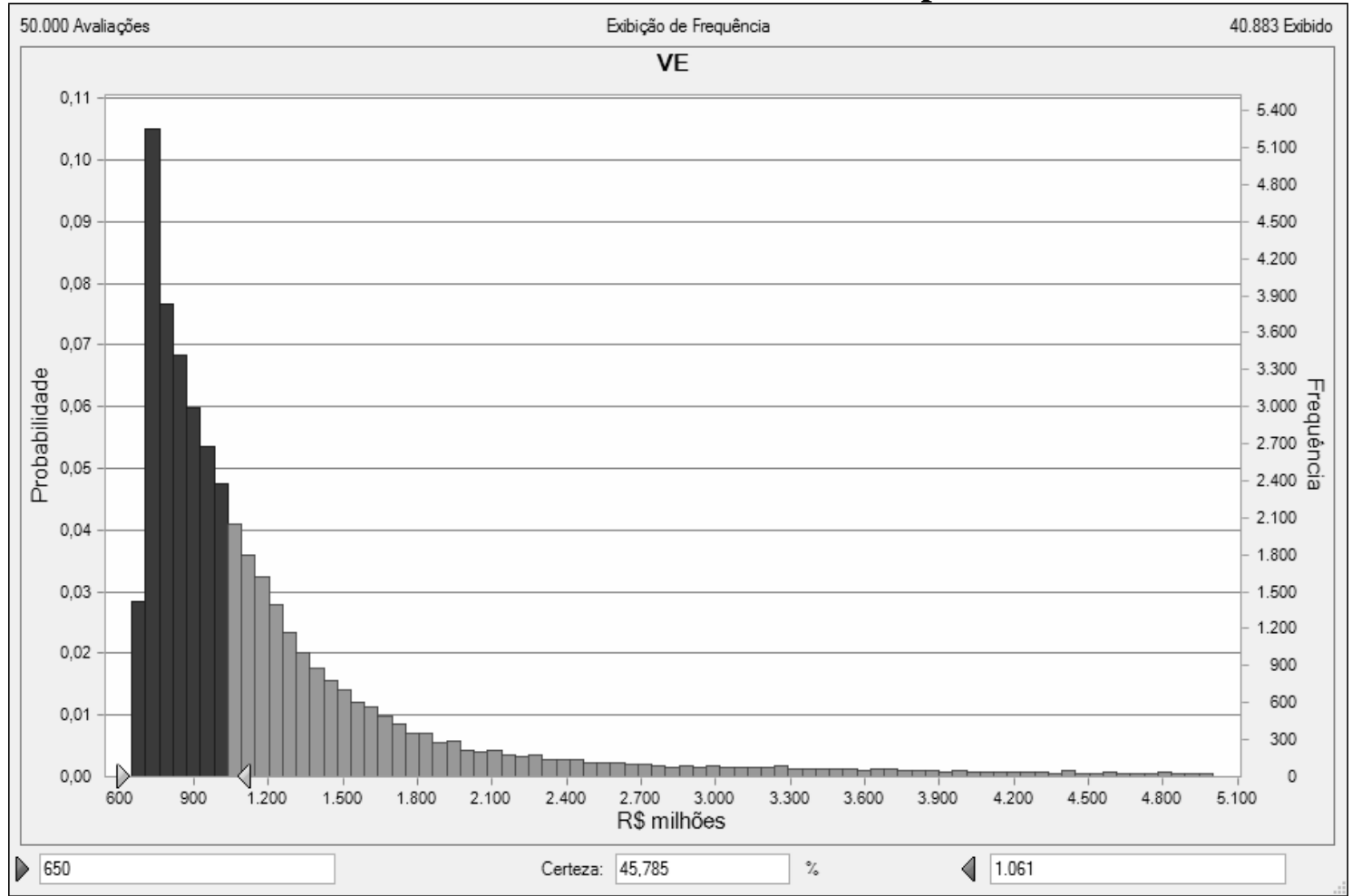

Fonte: Elaboração própria, com auxílio do Oracle Crystal Ball ${ }^{\circledR}$

A partir da análise do Gráfico 1 observa-se que, com base em todos os pressupostos adotados nesta pesquisa, há $45,8 \%$ de probabilidade de que o valor da CEB Distribuição S.A. esteja entre R \$ 650 milhões e $\mathrm{R} \$ 1.061$ milhões. Nesses casos, o valor da empresa não seria suficiente para justificar o investimento do ponto de vista financeiro, pois o retorno seria inferior ou igual ao valor investido.

O Gráfico 2, gráfico de sensibilidade, indica quais variáveis são mais relevantes em relação à variação do valor da empresa. Pela análise desse gráfico, nota-se, como já era esperado, que os resultados dos anos mais próximos foram mais relevantes na estimativa. A variável que mais apresenta influência na variação do valor da empresa é o retorno de mercado $\left(R_{m}\right)$, sendo relevante nos anos de 2017 a 2024. Esse fato está provavelmente relacionado ao elevado desvio padrão utilizado como pressuposto dessa variável ao longo dos anos projetados, que representa a grande variação dos retornos do mercado. 
Gráfico 2 - Sensibilidade do valor da empresa

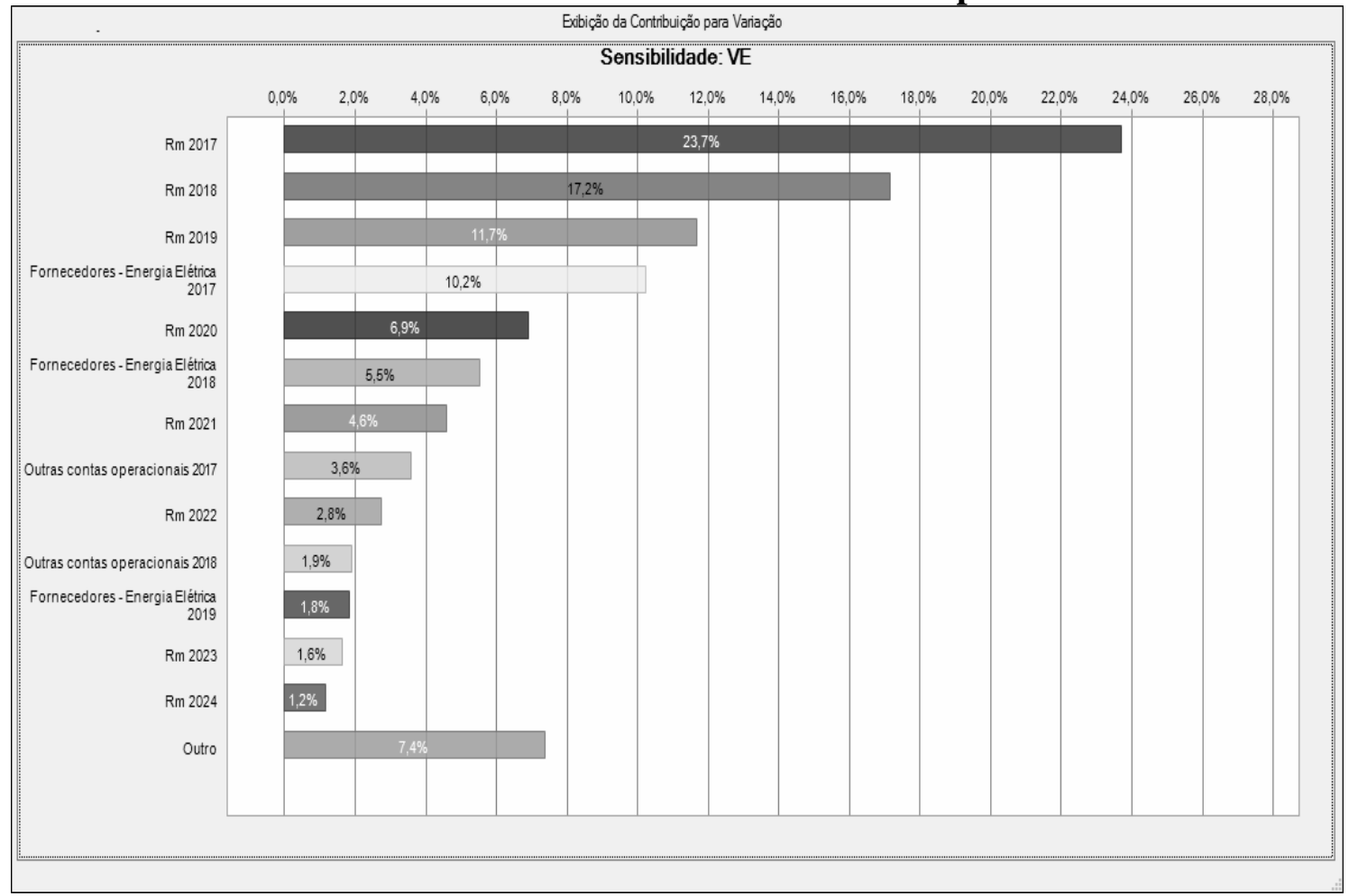

Fonte: Elaboração própria, com auxílio do Oracle Crystal Ball ${ }^{\circledR}$

Outras variáveis que se destacaram foram os valores projetados da conta "Fornecedores - Energia elétrica" de 2017 a 2019 e o valor do agregado de "Outras contas operacionais" de 2017 e 2018.

\section{CONSIDERAÇÕES FINAIS}

Este trabalho se propôs a calcular o valor da CEB Distribuição S.A. a partir do método fluxo de caixa descontado e analisar qual o significado do valor obtido para a qualidade do gasto público referente ao investimento de recursos públicos nessa entidade. $O$ valor encontrado para a empresa foi menor do que o esperado, representando que valor presente dos retornos projetados foi inferior ao valor investido na empresa. É importante ressaltar que o valor encontrado, devido à metodologia de pesquisa e procedimentos realizados para seu cálculo, representa o valor da CEB Distribuição S.A. caso a entidade continue a seguir sua linha histórica de desempenho.

O valor da empresa calculado pelo fluxo de caixa descontado pode ser utilizado para evidenciar a qualidade dos gastos públicos realizados na CEB Distribuição S.A.. Os resultados desta pesquisa indicam que os gastos públicos realizados indiretamente pelo Governo do Distrito Federal na CEB Distribuição S.A. não produzirão o retorno econômicofinanceiro esperado. Essa situação pode ser entendida como transferência de renda proveniente da população que contribui com impostos, os quais representam a maior parcela das receitas públicas. Além disso, o valor da empresa para o acionista obtido permitiu inferir que o investimento da controladora integral Companhia Energética de Brasília na CEB Distribuição S.A. apresenta um valor recuperável menor do que o contábil.

Considerando a incerteza do processo de avaliação de empresas realizou-se uma análise de sensibilidade do valor da empresa, que considerou vários cenários a partir dos pressupostos definidos para esta avaliação. O resultado obtido foi que há 45,8\% de probabilidade de que o valor da empresa não seja suficiente para justificar, sob a perspectiva financeira, o investimento nela realizado. 
Este resultado pode estar relacionado às dificuldades de gestão que empresas estatais apresentam em comparação a empresas privadas, devido a fatores como a menor discricionariedade na tomada de decisões, acarretada principalmente pela necessidade de cumprimento de procedimentos burocráticos adicionais, não obrigatórios para empresas privadas.

A conclusão do presente trabalho pode servir como guia de ação na área pública, por demonstrar a necessidade de melhoria na qualidade dos gastos públicos realizados na empresa analisada, situação que pode se estender a outras empresas estatais brasileiras. Destarte, sugere-se a realização de pesquisas em que se utilize a metodologia apresentada para analisar outras empresas estatais do país.

\section{REFERÊNCIAS}

ABRANCHES, Sérgio. Reforma regulatória: conceitos, experiências e recomendações. Revista do Serviço Público, v. 50, n. 2, p. 19-50, 1999.

ANEEL. Agência Nacional de Energia Elétrica. Resolução Autorizativa no 318, de 14 de setembro de 2005. Anui com a segregação de atividades, transferência de concessões e reestruturação societária da Companhia Energética de Brasília - CEB. Disponível em: < http://www2.aneel.gov.br/cedoc/rea2005318.pdf>. Acesso em: 16 fev. 2017.

BRADESCO. Projeções Bradesco Longo Prazo. Disponível em:

$<$ https://www.economiaemdia.com.br/vgn-exttemplating/v/index.jsp?vgnextoid=065098037f782310VgnVCM100000882810acRCRD\&vgn extfmt=default $>$. Acesso em: 06 fev. 2017.

BRASIL. Lei $\mathbf{n}^{\mathbf{0}}$ 6.404, de 15 de dezembro de 1976. Dispõe sobre as Sociedades por Ações. Disponível em: <http://www.planalto.gov.br/ccivil_03/leis/L6404consol.htm>. Acesso em: 31 jan. 2017.

Lei $\mathbf{n}^{\circ} \mathbf{1 0 . 8 4 8}$, de 15 de março de 2004. Dispõe sobre a comercialização de energia elétrica. Disponível em: <http://www.planalto.gov.br/ccivil_03/_ato2004-2006/2004/lei/110. 848.htm>. Acesso em: 16 fev. 2017.

Relatório resumido da execução orçamentária demonstrativo da projeção atuarial do regime geral de previdência social orçamento da seguridade social 2017 a 2060. Diário Oficial da União, Brasília, DF, n. 21, p. 64-65, 30 jan. 2017.

CEB. Disponível em: <http://www.ceb.com.br/index.php/institucional-ceb-separator/cebdistribuicao-s-a>. Acesso em: 15 mai. 2017.

COMISSÃO DE VALORES MOBILIÁRIOS. Instrução CVM no 361, de 5 de março de 2002. Dispõe sobre o procedimento aplicável às ofertas públicas de aquisição de ações. Disponível em: <http://www.cvm.gov.br/legislacao/inst/inst361.html>. Acesso em: 10 abr. 2017

COMITÊ DE PRONUNCIAMENTOS CONTÁBEIS. Pronunciamento Técnico CPC 00 (R1): Estrutura Conceitual para Elaboração e Divulgação de Relatório Contábil. 2011. 2010. Pronunciamento Técnico CPC 01 (R1): Redução ao Valor Recuperável de Ativos. 
COSTA, Luis; COSTA, Luiz; ALVIM, Marcelo. Valuation: Manual de Avaliação e Reestruturação Econômica de Empresas. 1 ed. São Paulo: Atlas, 2010.

DAMODARAN, Aswath. Avaliação de Investimentos. 2. ed. Qualitymark. 2010.

. Finanças corporativas: teoria e prática. 2. ed. Bookman. 2004.

January 2017 Data Update 5: A Taxing Year Ahead? Disponível em: $<$ http://aswathdamodaran.blogspot.com.br/2017/01/january-2017-data-update-5-taxingyear.html>. Acesso em: 27 jan. 2017.

The little book of valuation: how to value a company, pick a stock and profit. John Wiley \& Sons, 2011.

FERNÁNDEZ, Pablo. 102 errores en valoraciones de empresas. IESE Business School paper, Documento de investigación DI, n. 681, 2007.

Valuation methods and shareholder value creation. Academic Press, 2002.

GIL, Antonio Carlos. Como elaborar projetos de pesquisa. 4. ed. São Paulo: Atlas, 2002.

INTERNATIONAL FEDERATION OF ACCOUNTANTS (IFAC). International Good Practice Guidance: Project Appraisal Using Discounted Cash Flow (DCF), 2008.

INTERNATIONAL VALUATION STANDARDS COUNCIL (IVSC). Valuations of Specialised Public Service Assets. Exposure Draft, 2013.

KOLLER, Tim; GOEDHART, Marc; WESSELS, David. Valuation: measuring and managing the value of companies. 6 ed. John Wiley \& Sons, 2015.

MARTELANC, Roy; PASIN, Rodrigo; PEREIRA, Fernando. Avaliação de Empresas: Um Guia para Fusões \& Aquisições e Private Equity. São Paulo: Pearson, 2009.

MARTINS, Eliseu (Org.). Avaliação de empresas: da mensuração contábil à econômica. São Paulo: Atlas, 2001.

MUSGRAVE, Richard; MUSGRAVE, Peggy. Finanças Públicas. Ed. Campus. Universidade de São Paulo, 1980.

MYERS, Stewart. Interactions of corporate financing and investment decisions - Implications for capital budgeting. Journal of Finance, 29(1), 1-25, 1974.

PIRES, Beatriz. As empresas estatais e o controle societário do Estado. Revista JC, n. 145, 2012.

PÓVOA, Alexandre. Valuation: Como precificar ações. Rio de Janeiro: Elsevier, 2012.

SANTOS, José. Avaliação de empresas: cálculo e interpretação do valor das empresas um guia prático. 2 ed. Saraiva. 2008. 
SOUZA, Marcelo. Quantificação das incertezas na avaliação de projetos: o modelo utilizado na Agência de Fomento do Estado da Bahia. Dissertação (Mestrado) - Programa de Pós-graduação em Engenharia de Produção, Universidade Federal de Santa Catarina, Florianópolis, 2004.

YIN, Robert. Estudo de caso: planejamento e métodos. 2 ed. Porto Alegre: Bookman, 2001. 